\title{
COMBINED MACE \& MITROFANOFF PROCEDURE FOR TOTAL NEUROGENIC FECO-URINARY INCONTINENCE - A CASE REPORT
}

\author{
KMD ISLAM ${ }^{1}, \mathrm{R} \mathrm{AMIN}{ }^{2}, \mathrm{ASM}$ OLIULLAH ${ }^{3}, \mathrm{AKMK} \mathrm{BASHER}^{4}, \mathrm{~A} \mathrm{BISWAS}^{5}, \mathrm{~N} \mathrm{ISLAM}^{6}$
}

\begin{abstract}
:
Intractable fecal and urinary incontinence, often associated with myelomeningocele (MMC), usually prevents children from achieving physical and social independence. The Malone Antegrade Continence Enema (MACE) procedure, often performed in conjunction with a Mitrofanoff procedure to gain fecal \& urinary continence, can help these patients to attain a better quality of life. In patients, who underwent the combined Mitrofanoff and MACE procedures simultaneously, the success rate is- $83 \%$ satisfactory for both bowel \& urinary continence. With this procedure we report here, for the first time in Bangladesh, to the best of our knowledge, an association between two previously described techniques (the Mitrofanoff principle and MACE), that can solve the problem of dual incontinence in children with MMC. The case involved a 14 years old boy with total neurogenic feco-urinary incontinence following excision \& repair of MMC at the age of 4 months. After the surgery, the boy is continent with normal renalfunction.
\end{abstract}

Key words: Myelomeningocele (MMC), Faecal\& Urinary incontinence, Mitrofanoff procedure, MACE procedure.

1. Dr. KM Didarul Islam, Associate Professor, Department of Paediatric Surgery, BSMMU

2. Prof. Md. Ruhul Amin, Professor \& Chairman, Department of Paediatric Surgery, BSMMU

3. Dr. Abu Saleh Md. Oliullah, Assistant Professor, Department of Paediatric Surgery, BSMMU

4. Dr. A. K. M. Khairul Basher, Resident, Phase-B, Department of Paediatric Surgery, BSMMU

5. Dr. AmitavaBiswas, Resident, Phase-B, Department of Paediatric Surgery, BSMMU

6. Dr. Nazrul Islam, Medical Officer, Department of Paediatric Surgery, BSMMU

Correspondence to : Dr. KM Didarul Islam, Associate Professor, Department of Paediatric Surgery, BSMMU, E-mail: didar_ps@yahoo.com

\section{Introduction:}

Fecal and urinary incontinence are the serious complication of children with profound personal and family impacts. ${ }^{[1]}$ The affected children present with a history of voluntary and/or involuntary passage of stools \& urine into the underwear. ${ }^{[2]}$ The characteristic aroma of feces in these children predisposes them to stigmatization, rejection and bullying at school \& at the society, which subsequently result in school avoidance and social withdrawal. ${ }^{[3]}$ Also, hydronephrosis, reflux and renal failure are serious complications that occur in patients with neurogenic bladder associated with MMC. When the bladder compliance is lost, it is imperative to carry out surgery aimed at reducing bladder storage pressure. An ileocystoplasty, and for patients not suitable for intermittent catheterization, using the Mitrofanoff principle to form a continent stoma and the subsequent closure of the bladder neck, can be used. Physicians now frequently employ the MACE technique simultaneously with reconstruction of the lower urinary tract in patients with structural and neurogenic fecal and urinary incontinence, especially caused by congenital conditions such as MMC. In a recently recorded report the success of the combined Mitrofanoff and MACE procedures rate is an $83 \%$ satisfactory bowel control and an $83 \%$ urinary continence for neuropathic patients ${ }^{[18]}$. We report here, for the first time in Bangladesh, to the best of our knowledge, the initial success story of the combined Mitrofanoff and MACE procedures to address the dual incontinence in a boy of 14 years following excision \& repair of MMC at the age of 4 months. 


\section{Case:}

Our patient, fourteen years old boy presented to us with $\mathrm{H} / \mathrm{O}$ excision \& repair of MMC at the age of 4 months, associated with total neurogenic fecal and urinary incontinence. The boy was born with MMCassociated with fecal \& urinary incontinence. At the age of 4 months the boy underwent excision and repair of MMC at the Department of Neuro Surgery, Dhaka Medical College. But 8 days after discharge from hospital, he developed CSF leaking from the wound site due to trauma, despite there was no leaking during the time of discharge. After 7 days of the incidence the boy again admitted to that department and subsequently after the infection subsided, the wound had been re-repaired. He discharged home after healing of local wound though his associated problems i.e. fecal \& urinary incontinence persists. His fecal \& urinary incontinence was so intractable that, few months later he developed chronic sacral ulcers, which was managed conservatively. The boy admitted in school at the age of 5 years. But after few days of admission, he extracted from school due to special aroma. As his parents are poor and illiterate, further he has never been taken to any hospital for treatment of his problem since excision \& repair of MMC. On April 10, 2015, the boy admitted into the Department of Paediatric Surgery, BSMMU for the treatment of his problem. After admission, some investigations were performed. Intravenous Urography (IVU) revealed normal upper urinary tract with good excretory function though his bladder capacity was not satisfactory. Ultrasonography of KUB showed absence of prostate with bilateral early renal parenchymal disease with thickened bladder wall. His echocardiography revealed a small peri-membranous VSD with L-R shunt and for which consultation was taken from paediatric cardiologist. As he has no other comorbidities, the boy underwent combined MACE \& Mitrofanoff procedure simultaneously on 20.05.2015. Laparatomy was done by midline incision. Caecum and the appendix were identified. The appendix was found about $15 \mathrm{~cm}$ long (Fig.-1) which was divided into two parts- the proximal $1 / 3$ rd with its intact vascular pedicle of Ilio-caecal artery and the distal 2/3rd with its intact vascular pedicle of appendicular artery in the mesoappendix (Fig.-2). A segment of sigmoid colon, about $5-6 \mathrm{~cm}$ in length, was isolated along with its vascular pedicle. The bladder was divided longitudinally and neck of bladder was closed with 2/

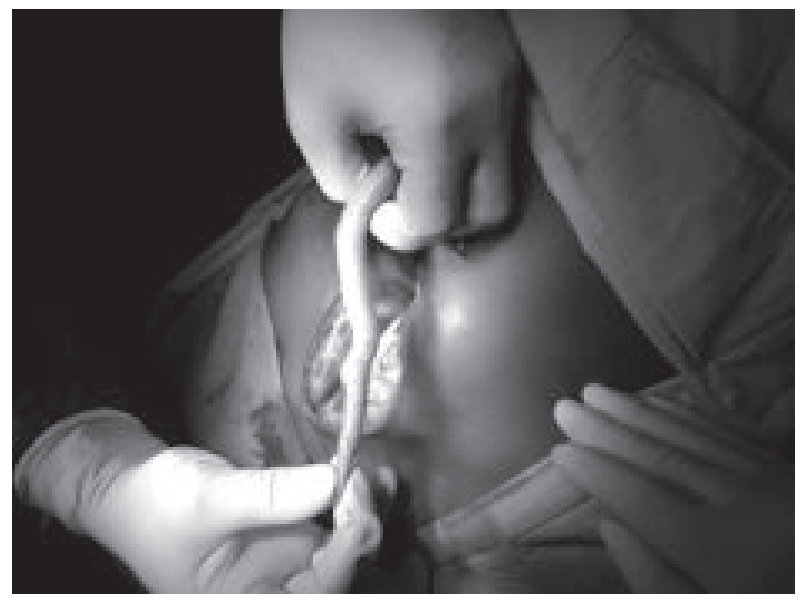

Fig-1: Undivided long appendix

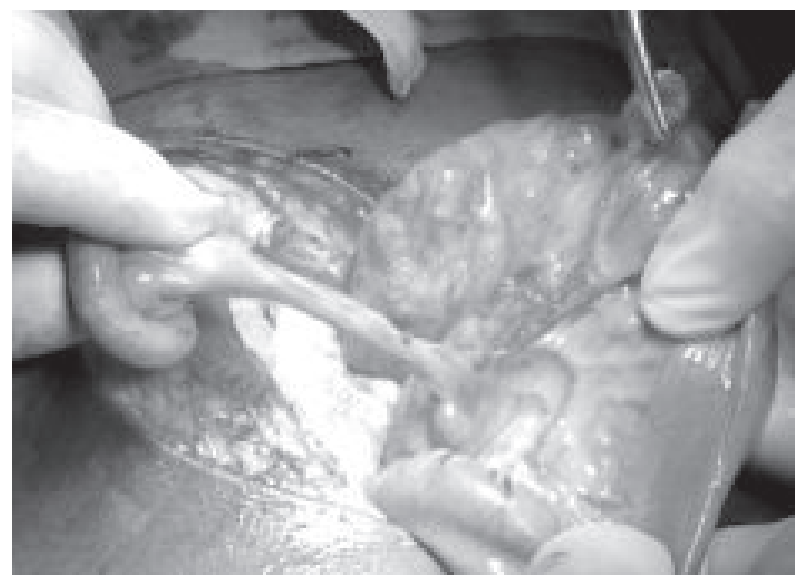

Fig-2: Divided appendix with vascular pedicle

0 vicryl. Augmentation cystoplasty was done with isolated segment of sigmoid colon. Then the isolated appendix was implanted on the posterior bladder wall \& the Mitrofanoff procedure was completed keeping the stoma infra-umbilically through the anterior abdominal wall. A $10 \mathrm{Fr}$. all silicon catheter was introduced as stent through the Mitrofanoff channel which was planned to keep for 14 days, after which, through this channel, assisted catheterization would be started. The bladder was inflated with normal saline and checked for any leaking. The proximal appendix was brought out to the right lower quadrant of abdomen to create a MACE channel. The continuity of gut was ensured by end to end anastomosis of sigmoid colon. Unfortunately, on $9^{\text {th }}$ post-operative day, the boy developed urinary ascitis and re exploration was done on 13th POD, as conservative management failed. On re- explorationwe found leaking of urine through a small point at the bladder neck which had been repaired. Peritoneal toileting was done, Mitrofanoff stent was removed and abdomen was closed leaving 
an $18 \mathrm{Fr}$. Foley's catheter into the bladder, which removed on $7^{\text {th }}$ POD of re-exploration. After 10 days of re-exploration, $\mathrm{CIC}$ and antegrade enema were started and the boy had been dry since the operation. Initially the antegrade enema was commenced on every day and after 2 weeks, it was every alternate day. The boy discharged home on $37^{\text {th }}$ POD of reexploration as he could perform $\mathrm{CIC}$ and antegrade enema by himself. On first follow up, after 21 days he found dry with normal renal function except mild UTI.

\section{Discussion:}

Patients with neurogenic voiding dysfunction usually have coexisting neurogenic bowel problems. Impaired bowel evacuation ( $27 \%$ to $54 \%$ of spinal cord injury patients) can lead to both severe fecal impaction and fecal incontinence. Traditional management includes stool softeners, bulking agents, digital rectal stimulation, suppositories, and enemas. In 1990, Malone and coworkers ${ }^{13}$ reported their initial experience with 5 patients combining the principles of antegrade colonic washout and the Mitrofanoff nonrefluxing catheterizable channel to produce a continent catheterizable colonic stoma. The intention was that antegrade washouts delivered by this route would produce complete colonic emptying and thereby prevent soiling

Whereas the Mitrofanoff principle in the surgical management of urinary incontinence, for creation of a continent catheterizable stoma using the appendix has been a mainstay in the armamentarium of pediatric urologists and reconstructive surgeons since it was originally described in $1980^{5}$. This principle involves the use of a small-caliber tube implanted into a compliant bladder or reservoir with a nonrefluxing anastomosis to provide a convenient and effective method of emptying the bladder. Applications of this technique have expanded to include the use of ureter, tapered ileum, stomach, tubularized bladder flaps, and transverse tubularized bowel, as originally described by Yang ${ }^{6}$ and Monti et al $^{7}$ and later modified by Casale $^{8}$.

In 1990, Malone ${ }^{9}$ adapted the concept of Mitrofanoff for a catheterizable continent urinary stoma to children with intractable fecal incontinence by describing the continent cutaneous appendicocecostomy. In essence, this technique allows periodic catheter access to the right colon, whereby an enema can be administered to eliminate contents of the large bowel on a timely, reliable basis. The Malone antegrade continence enema (MACE) procedure has since been applied in several pathologic conditions when all other conservative attempts to control fecal incontinence or severe constipation have failed and the only remaining option has been a colostomy. ${ }^{10}$

It has been common in the past for many patients, especially pediatric patients with neurogenic incontinence secondary to myelomeningocele, to have undergone a successful urinary antiincontinence procedure only to remain in diapers because of continued fecal soiling. Because of physical limitations, many of these children have depended on a family member or other caregiver to render standard retrograde enemas, digital manipulation, and/or other medical therapies to deal with fecal problems. In addition to this dependence, fear of accidents and foul odors has impeded the attainment of independent living and the level of socialization that many of these patients might otherwise have achieved. ${ }^{11}$

Paediatric surgeons now frequently employ the MACE technique simultaneously with reconstruction of the lower urinary tract in patients with structural and neurogenic fecal and urinary incontinence, especially caused by congenital conditions such as myelomeningocele. The reported success of the MACE procedure, as defined by continence, is on the order of $90 \%$ for neuropathic patients. ${ }^{12}$

Since its introduction in 1990, several modifications to the MACE procedure have been reported in the literature. Sugarman and associates ${ }^{14}$ had good short-term results with the MACE procedure using a tubularizedileal segment (Monti principle) in the absence of an appendix. Goepel and coworkers ${ }^{15}$ described an antegrade colonic enema via an orthotopic continent appendiceal stoma as a safe and highly effective treatment modality for fecal incontinence in patients with neurogenic bowel dysfunction for whom nonsurgical management had failed. Bruce and associates ${ }^{16}$ reported the use of a gastric segment in performing the antegrade continence enema procedure in patients with refractory fecal incontinence. At a mean postoperative follow-up of 22.4 months, all patients (4 women and 3 men) were continent and used antegrade continence enema irrigation every other day on average.

In 1996, Koyle and colleagues ${ }^{17}$ reported splitting the appendix to provide both the Mitrofanoff and MACE stomas. The technique involves dividing the appendix such that the distal portion used for the Mitrofanoff urinary stoma is supplied by the appendiceal artery, while the proximal stump is fed by the ileocecal artery. Since then, other investigators 
using synchronous Mitrofanoff and MACE procedures have reported successful outcomes for patients with urinary and bowel incontinence. Mor and coworkers ${ }^{18}$ recorded an $83 \%$ satisfactory bowel control and an $83 \%$ urinary continence rate in 18 patients who underwent the combined Mitrofanoff and MACE procedures. A stomal revision rate of $38 \%$ was noted at the MACE site and $33 \%$ at the Mitrofanoff site.

Though, this is the first time in Bangladesh that we have combined the Mitrofanoff and MACE procedures simultaneously to address the dual incontinence in this boy of $14 \mathrm{yrs}$. old, with post excised MMC, the initial result, in terms of remaining dry for the boy is encouraging. Further follow up is needed to assess long term results.

\section{Conclusion:}

In Bangladesh, where social stigma against incontinence is more intense and parents arereluctant to practice simple $\mathrm{CIC}$ routine to keep their kids free from soiling problems; the combined MACE and Mitrofanoff procedure used simultaneously can be the procedure of choice for the children who are suffering from total neurogenic feco-urinary incontinence.

\section{References:}

1. Bernard-Bonnin AC, Haley N, Belanger S, Nadeau D. Parental and patient perceptions about encopresis and its treatment. J DevBehavPediatr 1993; 14: 397-400.

2. Weissenberg S. Uber Encopresis. Zeitschrift fur Kinderheilkd 1926; 40: 674.

3. Joinson C, Heron J, Butler U, von Gontard A. Psychological differences between children with and without soiling problems. Pediatrics 2006; 117: 1575-84.

4. Roberts JP, Moon S, Malone PS. Treatment of neuropathic urinary and faecal incontinence with synchronous bladder reconstruction and the antegrade continence enema procedure. $\mathrm{Br} \mathrm{J}$ Urol. 1995;75:386-389.

5. Mitrofanoff P: Trans-appendicular continent cystostomy in the management of the neurogenic bladder [inFrench]. ChirPediatr 1980, 21:297305.PubMed

6. Yang $\mathrm{WH}$ Yang needle tunneling technique in creating antireflux and continent mechanisms. J Urol 1993. 150:830-834.PubMed

7. Monti PR, Lara RC, Dutra MA, de Carvalho JR: New techniques for construction of efferent conduits based on the Mitrofanoff principle. Urology 1997, 49:112-115.PubMedView Article

8. Casale AJ: A long continent ileovesicostomy using a single piece of bowel. J Urol 1999, 162:1743-1745.PubMedView Article

9. Malone PS, Ransley PG, Kiely EM. Preliminary report: the antegrade continence enema. Lancet. 1990;336:1217-1218.

10. Griffiths DM, Malone PS. The Malone antegrade continence enema. J Pediatr Surg. 1995; 30: 68-71.

11. Ellsworth PI, Webb HW, Crump JM, et al. The Malone antegrade continence enema enhances the quality of life in children undergoing urological incontinence procedures. J Urol. 1996; 155:1416-1418.

12. Roberts JP, Moon S, Malone PS. Treatment of neuropathic urinary and faecal incontinence with synchronous bladder reconstruction and the antegrade continence enema procedure. $\mathrm{Br} J$ Urol. 1995;75:386-389.

13. AlbahaBarqawi, MB, Peter D. Furness III, MD, AbelardoErregon, MD, Martin A. Koyle, MD et al. New Innovations in Continent Catheterizable Stomas.

14. Sugarman ID, Malone PS, Terry TR, Koyle MA. Transversely tubularizedileal segments for the Mitrofanoff or Malone antegrade colonic enema procedures: the Monti principle. Br J Urol. 1998;81:253-256.

15. Goepel M, Sperling $H$, Stohrer $M$, et al. Management of neurogenic fecal incontinence in myelodysplastic children by a modified continent appendiceal stoma and antegrade colonic enema. Urology. 1997;49:758-761.

16. Bruce RG, el-Galley RE, Wells J, Galloway NT. Antegrade continence enema for the treatment of fecal incontinence in adults: use of gastric tube for catheterizable access to the descending colon. J Urol. 1999;161:1813-1816.

17. Koyle MA, Wasman SW, Duque M. Applications and modification of the Malone antegrade continence enema (MACE) with coincidental urinary tract reconstruction: the dual role of the appendix. J Urol. 1996;155(suppl):458A. Abstract 698.

18. Mor Y, Quinn FM, Carr B, et al. Combined Mitrofanoff and antegrade continence enema procedures for urinary and fecal incontinence. J Urol. 1997;158:192-195. 